\title{
Experimental Study on Strain Reliability of Embroidered Passive UHF RFID Textile Tag Antennas and Interconnections
}

\author{
Xiaochen Chen, ${ }^{1}$ Aruhan Liu, ${ }^{2}$ Zhigang Wei, ${ }^{2}$ Leena Ukkonen, ${ }^{1}$ and Johanna Virkki ${ }^{1}$ \\ ${ }^{1}$ Department of Electronics and Communications Engineering, Tampere University of Technology, \\ P.O. Box 692, 33101 Tampere, Finland \\ ${ }^{2}$ Department of Electronic Engineering, City University of Hong Kong, 83 Tat Chee Avenue, Kowloon, Hong Kong \\ Correspondence should be addressed to Xiaochen Chen; xiaochen.chen@tut.fi
}

Received 24 October 2016; Revised 21 December 2016; Accepted 16 January 2017; Published 2 February 2017

Academic Editor: Guy A. E. Vandenbosch

Copyright (C) 2017 Xiaochen Chen et al. This is an open access article distributed under the Creative Commons Attribution License, which permits unrestricted use, distribution, and reproduction in any medium, provided the original work is properly cited.

\begin{abstract}
We present embroidered antennas and interconnections in passive UHF RFID textile tags and test their strain reliability. Firstly, we fabricate tag antennas on two different stretchable fabric substrates by five different embroidery patterns and choose the most stretchable ones for testing. Next, the tag ICs are attached by sewing and gluing, and the tag reliability during repeated stretching cycles is evaluated through wireless measurements. Initially, the chosen tags achieve read ranges of 6-8 meters and can strain up to $140-150 \%$ of their original length. After 100 stretching cycles to $80 \%$ of their maximum strain, the read ranges of the tags with glued interconnections are similar to the initial values. In addition, also the read ranges of the tags with sewed interconnections are still more than $70 \%-85 \%$ of their initial values. However, some challenges with the reproducibility need to be solved next.
\end{abstract}

\section{Introduction}

Passive UHF (ultra-high frequency) RFID (radio frequency identification) inspired technology has been recognized as a compelling approach to achieve versatile energy efficient wireless technologies for future WBANs (wireless body area networks) [1-4]. The development of WBAN technologies has gained a lot of research attention during the recent years as they can offer remarkable benefits for healthcare and welfare sectors [1-5], as well as novel sports-related applications $[5,6]$.

Light-weight, flexible antennas and interconnections are needed for these versatile wireless systems and wearable applications also require the antennas and interconnections to be an integral part of clothing. In addition, antennas and interconnections in wearable applications need to endure different mechanical stresses, such as bending and stretching. Additive manufacturing methods have been found to provide the foundation for these novel applications, as they have the capacity to produce conductors on soft and stretchable materials, such as textiles [7-9]. One highly potential additive textile antenna fabrication method is embroidery with conductive yarn. Sewing is a simple manufacturing method with great possibilities due to its compatibility with various textile materials [9-13]. In embroidery, we have a full control of the conductive pattern: shape, stitch density, and stitch type [9]. In addition to conductor and antenna fabrication, sewing has also been found to be a highly potential method for embedding electrical interconnections into textile materials [9-13].

The effects of the antenna sewing pattern on the tag performance have been previously studied in $[9,14]$. Also the strain reliability of sewed interconnections in general has been recently studied [15]. However, to the best of our knowledge, this is the first strain reliability study of embroidered RFID tag antennas and interconnections. During normal movement, the human skin may stretch up to $15 \%-20 \%$, which means we need to implement antennas and interconnections that function well at least under such elongations [16].

In this study, dipole antennas for passive UHF RFID tags were embroidered on two different stretchable textile materials. After choosing the most suitable textile substrate and sewing patters, stretchable tag antennas were fabricated 


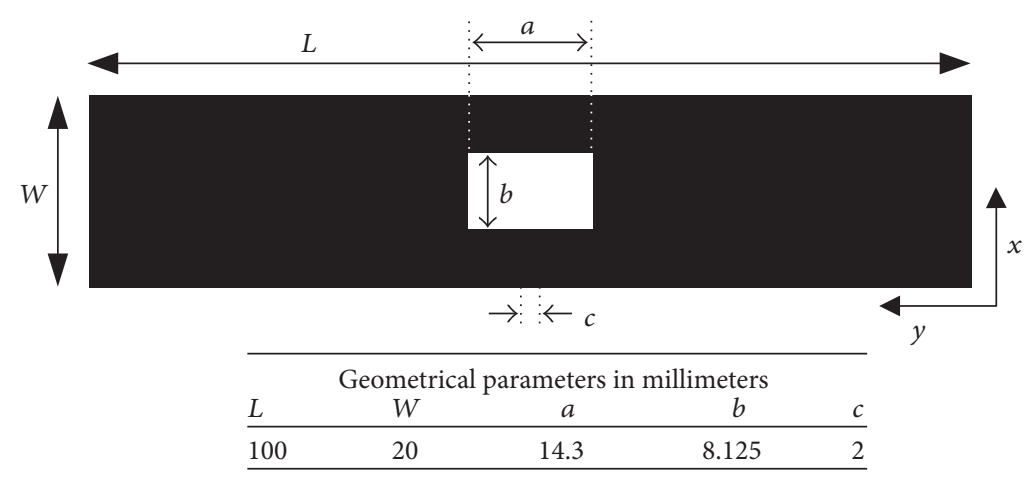

FIGURE 1: The tag antenna geometry.
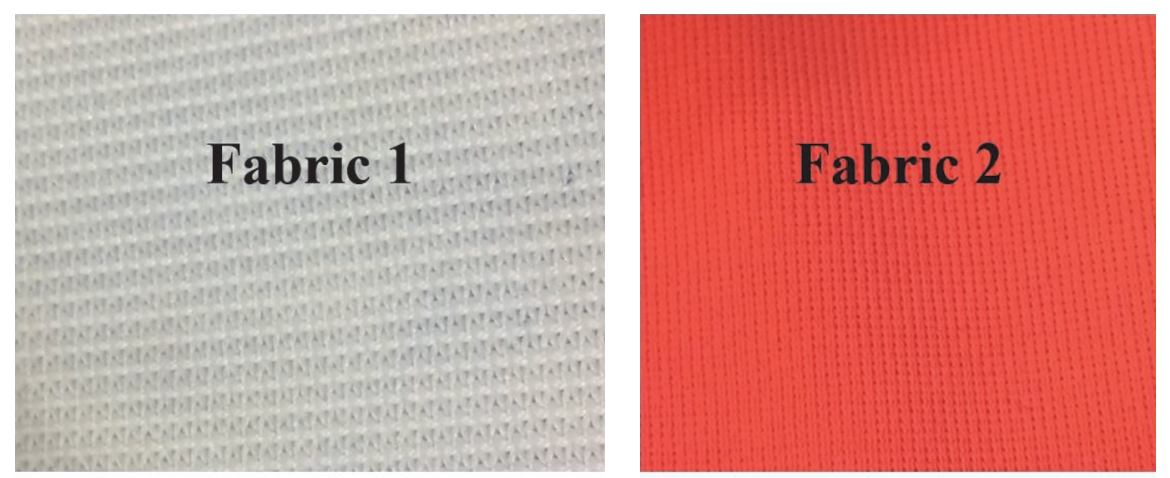

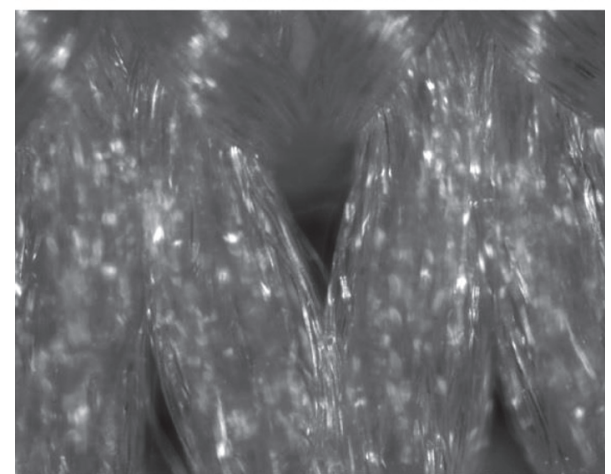

(a)

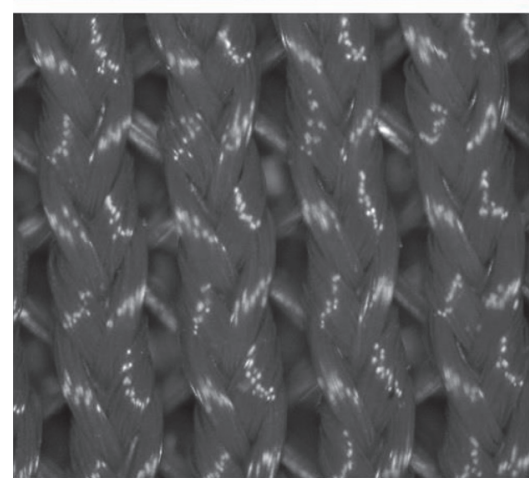

(b)

Figure 2: Photos and microscope pictures of Fabric 1 (a) and Fabric 2 (b), magnification $\times 5$.

by embroidery, tag ICs were attached by sewing and by gluing, and the tag reliability was tested under cyclic strain. The performance of the tags before and after testing was evaluated by wireless measurements.

\section{Tag Fabrication}

The studied tag antenna (shown in Figure 1) is a straight dipole, which is a widely used antenna in UHF RFID tags. This antenna has been successfully used in several UHF RFID studies $[7,8]$ and it originated from a strain reliability study of stretchable electrotextile and screen-printed tags [17].

The tag antennas were fabricated on two different stretchable fabrics (Fabric 1 is an elastic band and Fabric 2 is a mixture of viscose and polyester), by using five different embroidery patterns. The two fabric materials are shown in Figure 2. The used thread was multifilament silver plated thread (Shieldex multifilament thread 110f34 dtex 2-ply HC). The DC linear resistivity of the thread is $500 \pm 100 \Omega / \mathrm{m}$, and the diameter is approximately $0.16 \mathrm{~mm}$.

The simulated amplitude of the surface current $[\mathrm{A} / \mathrm{m}]$ on the dipole antenna at $915 \mathrm{MHz}$ is shown in Figure 3. In the simulation, $0.62 \mathrm{~W}$ was delivered to the antenna. As can be seen, the current density at $915 \mathrm{MHz}$ was high around the embedded inductive matching loop and the nearby antenna edges. Two of the studied embroidery patterns were fully embroidered antennas (numbers 1 and 2 in Figure 4), sewed vertically ( $x$-axis in Figure 1) and horizontally ( $y$-axis in Figure 1). We also fabricated two dipoles with optimized patterns (numbers 2 and 3 in Figure 4), where full vertical and 


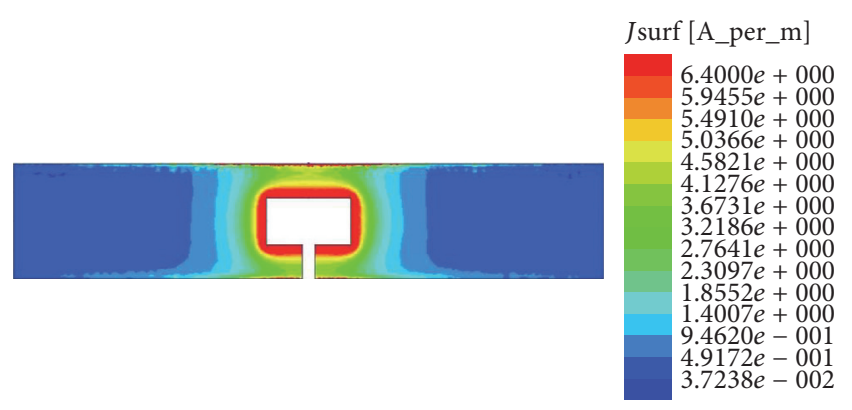

FIgURE 3: Current density on the dipole antenna.

horizontal patterns were used in places with highest surface current density and the rest of the antenna was only partially embroidered. In the fifth antenna, only the borders, that is, the contour of the antenna, were sewed (number 5 in Figure 4). It should be noted that the focus of this study was to test the strain reliability of the sewed antennas and interconnections, not to optimize the performance of the sewed antennas.

During sewing, it was noticed that embroidery on Fabric 2 is a major challenge because the cloth is soft, is thin, and has small tension. The ready-made tag antennas are shown in Figure 4, and for each tag type, we fabricated 5 antennas.

A vector network analyzer was used to measure the input impedance of the fabricated antennas. The port was glued with conductive silver epoxy on the position where the ICs were to be attached (the measurements were done without ICs to reduce the uncertainty). The input impedance of embroidered antennas with different patterns was measured at $915 \mathrm{MHz}$ and the results are shown in Table 1 . The reflection coefficient $\Gamma$ and return loss RL can be calculated by

$$
\begin{gathered}
\Gamma=\frac{Z_{A}-Z_{\mathrm{ic}}}{Z_{A}+Z_{\mathrm{ic}}} ; \\
\mathrm{RL}=-20 \log |\Gamma|,
\end{gathered}
$$

where $Z_{A}$ is the impedance of the antenna and $Z_{\text {ic }}$ is the impedance of the IC, which is $12.76-190.28 j$ at $915 \mathrm{MHz}$. $\Gamma$ and RL of the embroidered antennas are shown in Table 1.

Next, the strain ability of the different antennas was tested (see Table 2). Based on the stretching results and the experience gathered during sewing, Fabric 2 was omitted from further research and two sewing ways of making the antenna on Fabric 1 were chosen: contour pattern (Pattern 5) and partial vertical pattern (Pattern 3), as shown in Figure 4, marked with the red rectangles.

The used tag IC (integrated circuit) is NXP UCODE G2iL series RFID IC, provided by the manufacturer in a fixture patterned from copper on a plastic film (see Figure 5, where the IC strap structure is presented).

We attached the fixture pads to the antennas by embroidering over them with the conductive yarn during antenna fabrication, as shown in Figure 6. Finally, for comparison, we created another set of identical tags where the IC was attached using conductive epoxy (Circuit Works CW2400). See Figure 6 for the ready tags with ICs attached.

\section{Strain Testing and Wireless Measurements}

The tags were stretched a 100 times to $80 \%$ of their maximum strain and back, and the wireless performance was measured after 1, 10, 20, 30, 40, 50, and 100 stretching cycles. The stretching was done by hand with each stretching cycle lasting about 2 seconds. The reason for the 2 second cycle time was that if the stretching cycle was any shorter, that is, the stretching was done any faster, the glued antenna-IC attachments were easily broken (see Figure 7). This kind of reliability problem was not found in case of the sewed antenna-IC interconnections.

The wireless performance of the tags was evaluated using Voyantic Tagformance RFID measurement system. It contains an RFID reader with an adjustable transmission frequency $(800-1000 \mathrm{MHz}$ ) and output power (up to $30 \mathrm{dBm}$ ) and provides the recording of the backscattered signal strength (down to $-80 \mathrm{dBm}$ ) from the tag under test.

We wanted to focus on the performance of the sewed tags in absence of environmental stress factors and the effects of the proximity of the human body, so that the source of any observed performance variation is limited to the antenna fabrication parameters and effects of cyclic strain. We conducted all the measurements with the tag suspended on a foam fixture in an anechoic chamber.

During the test, we recorded the lowest continuous-wave transmission power (threshold power: $P_{\mathrm{th}}$ ) at which the tag remained responsive. The wireless channel from the reader antenna to the location of the tag under test was characterized using a system reference tag with known properties. As explained in [17], this enabled us to estimate the attainable read range of the tag $\left(d_{\text {tag }}\right)$ versus frequency from

$$
d_{\mathrm{tag}}=\frac{\lambda}{4 \pi} \sqrt{\frac{\operatorname{EIRP}}{\Lambda} \frac{P_{\mathrm{th}^{*}}}{P_{\mathrm{th}}}},
$$

where $\lambda$ is the wavelength transmitted from the reader antenna, $P_{\text {th }}$ is the measured threshold power of the sensor tag, $\Lambda$ is a known constant describing the sensitivity of the system reference tag, $P_{\mathrm{th}^{*}}$ is the measured threshold power of the system reference tag, and EIRP is the emission limit of an RFID reader given as equivalent isotropic radiated power. We present all the results corresponding to EIRP $=3.28 \mathrm{~W}$, which is the emission limit for instance in European countries.

\section{Results and Discussion}

In Figure 8, the read range results for two tags of each tag type are shown in a frequency range of $800-1000 \mathrm{MHz}$. As shown in Figure 8, the peak read ranges of the contour pattern tags with the sewed antenna-IC attachment are initially around 5.5-6.5 meters, whereas with the glued antenna-IC attachment, the read ranges can be slightly more than 7 meters. Thus, the glued antenna-IC interconnection seems to provide a better electrical connection. The peak read ranges of the Contour pattern tags are all around 900-920 MHz.

For the partial vertical pattern tags, the peak read ranges are around 7 meters with the glued IC and around 7-8 meters with the sewed IC. In this case the performance of both 


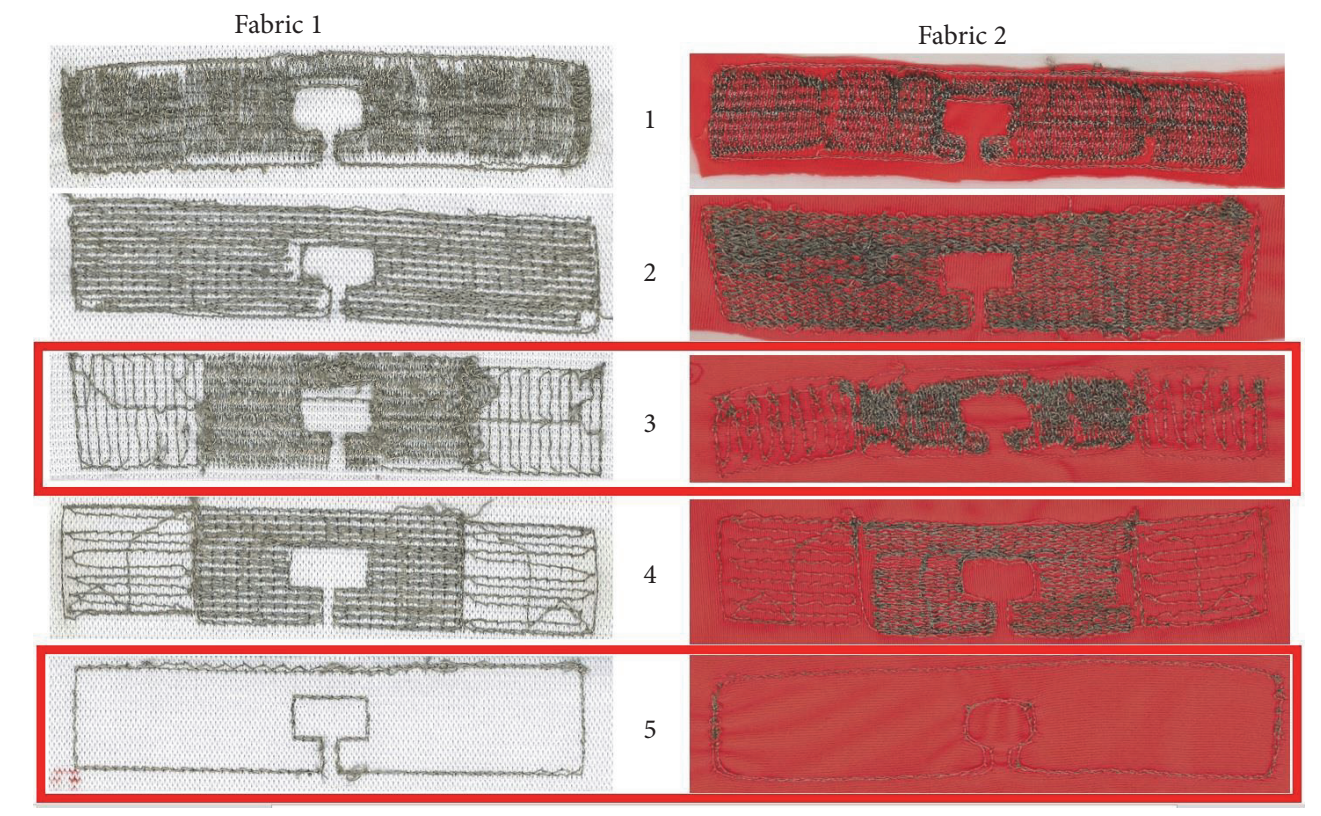

FIGURE 4: The 5 different antenna sewing patterns on both fabrics, the selected two sewing patters on Fabric 1 are marked with a red rectangular.

TABLE 1: Reflection coefficient and return loss of the antennas.

\begin{tabular}{lccc}
\hline & Input impedance & Reflection coefficient $(\Gamma)$ & Return loss $(\mathrm{RL})$ \\
\hline Contour pattern & $241.83-132.8 j$ & $0.05+0.3 j$ & $10.34 \mathrm{~dB}$ \\
Partial vertical pattern & $152.35-9.99 j$ & $-0.19-0.88 j$ & $1.1 \mathrm{~dB}$ \\
\hline
\end{tabular}

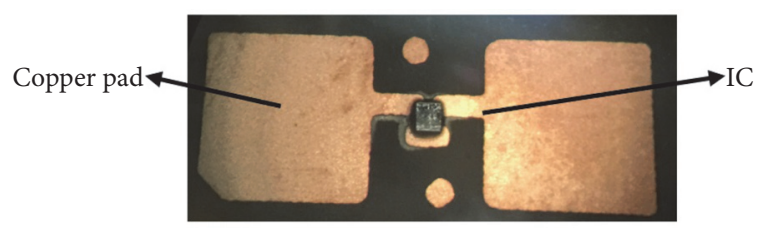

Figure 5: The used IC.
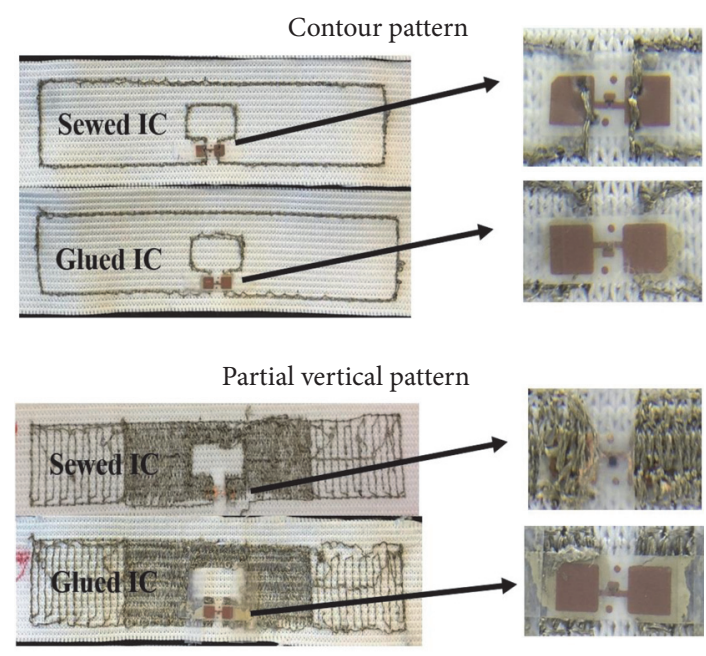

FIGURE 6: Ready-made tags and antenna-IC interconnections.

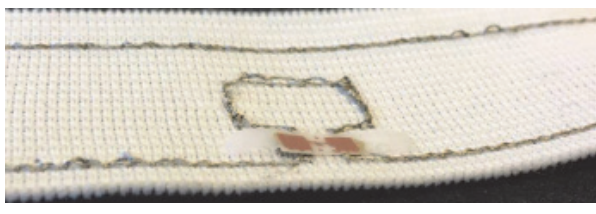

FIGURE 7: A broken glued antenna-IC interconnection.

interconnection types is similar. This can be explained by the fact that, in the contour pattern antenna, the IC was only attached by sewing a single line over the pads. In the partial vertical pattern, there are several stiches of the conductive yarn over the IC pads (see Figure 6), which makes the embroidered interconnection more conductive than in the case of the contour pattern. The peak read ranges of the tags with glued ICs are around $950 \mathrm{MHz}$, whereas the peak read ranges of the tags with the sewed ICs are around 910-920 MHz.

It can be noticed from Figure 8 that the reproducibility of the tags with the sewed interconnections is a challenge, whereas the read range figures of the tags with the glued interconnections are very similar. Thus, optimizing the antennaIC sewing patter for good reproducibility will definitely be the next step of this research.

Next, the tags were stretched 100 times to $80 \%$ of their maximum strain and the wireless performance was measured after 1, 10, 20, 30, 40, 50, and 100 stretching cycles. As can be seen from Figures 9 and 10, after 50 harsh stretching 


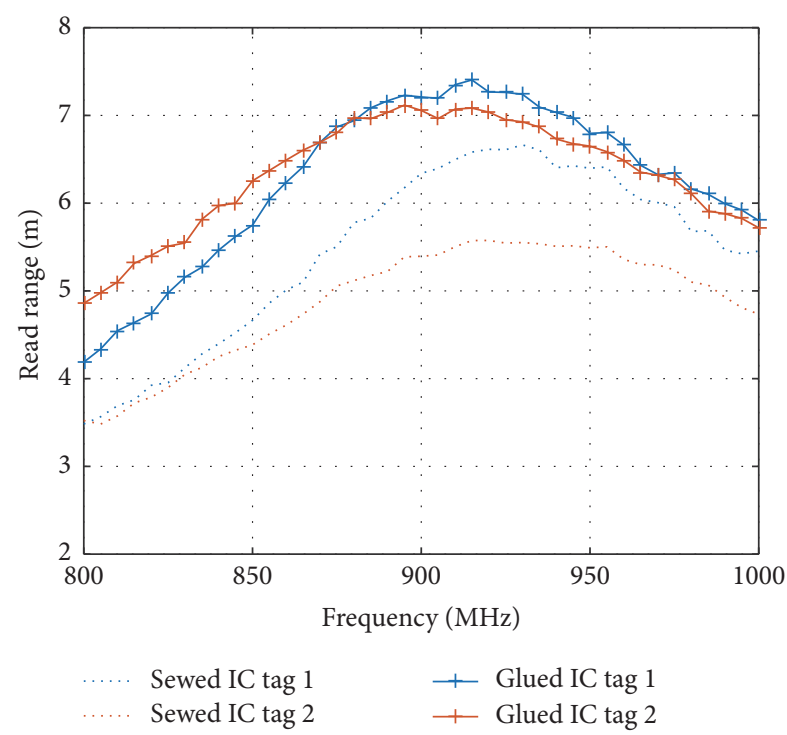

(a)

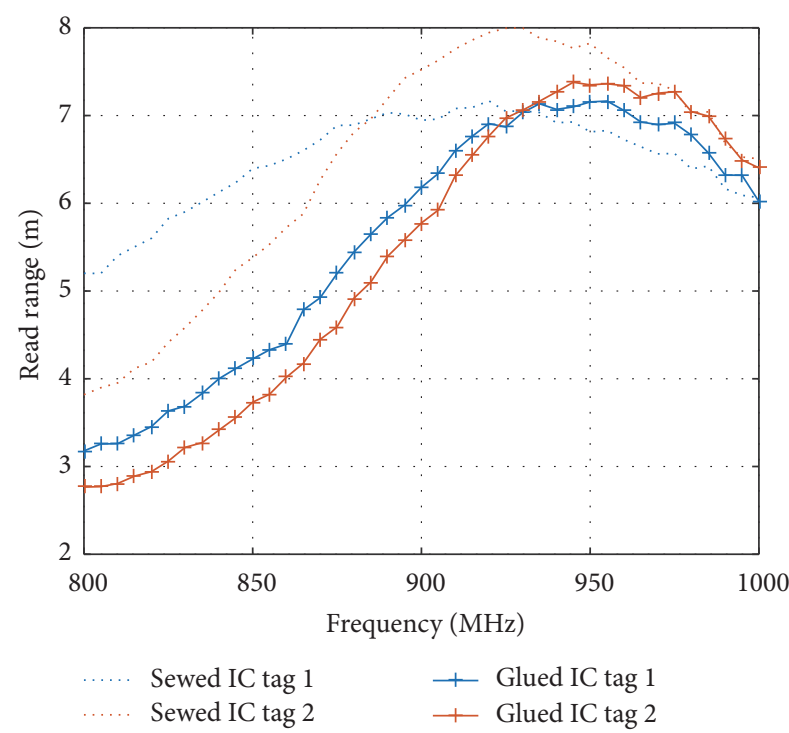

(b)

FIGURE 8: The initial attainable read ranges of the contour pattern (a) tag and partial vertical pattern (b) tag.

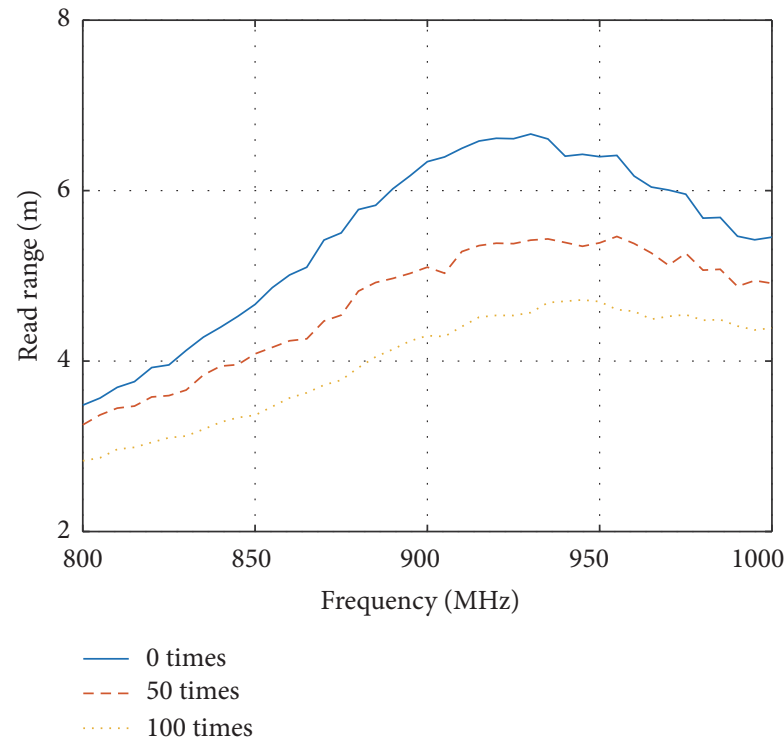

(a)

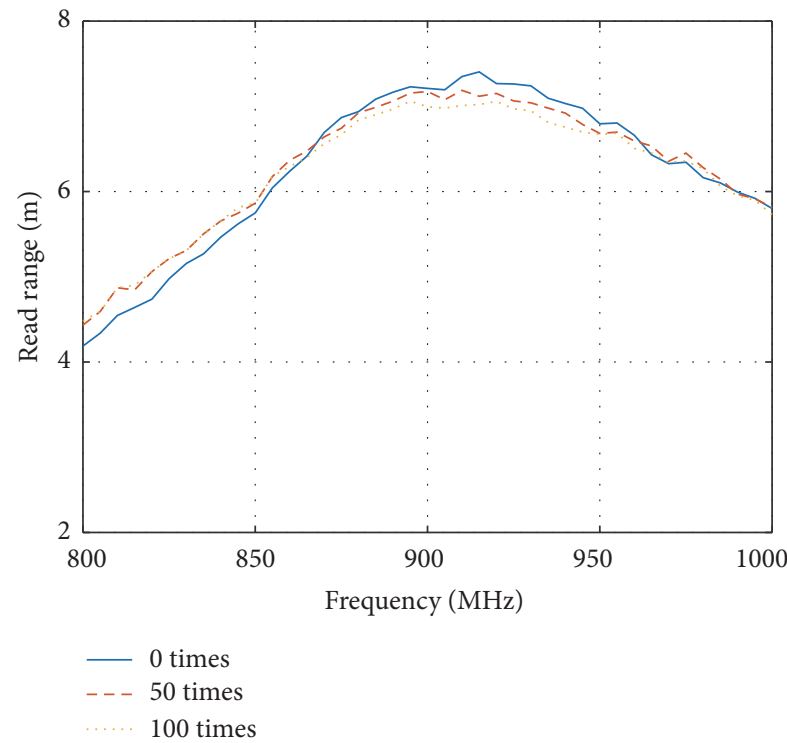

(b)

FIGURE 9: Repeated stretching test of contour pattern with sewed IC (a) and glued IC (b).

cycles, the peak read ranges of the tags with the sewed interconnections have decreased about 1 meter compared to the initial read ranges. After 100 stretching cycles, the read ranges of the contour pattern tags had still slightly decreased, to 4.7 meters, but the read ranges of the partial vertical pattern tags remained about the same as after 50 stretching cycles.

All the achieved read ranges are very promising. Based on our results, the sewed antenna-IC interconnections could be useful in future textile tag applications. However, the fabrication process needs to be further studied, for example, by trying different types of stiches around and through the IC pads. Also the challenges with the reproducibility need to be solved. As mentioned earlier, the tags with the glued antennaIC interconnections were not able to endure any faster stretching cycles than the used 2 seconds/cycle. Thus, also their reliability in normal use conditions, that is, embedded into clothing, can introduce challenges and requires further studying. On the other hand, the used type of stretching did not seem to have an effect on the read ranges of the tags with the glued ICs.

It should be noted here that this cycled stretching test was relatively harsh in comparison with the commonly expected field conditions of wearable antennas, with the exception of the special scenario where the tag on textile would be 


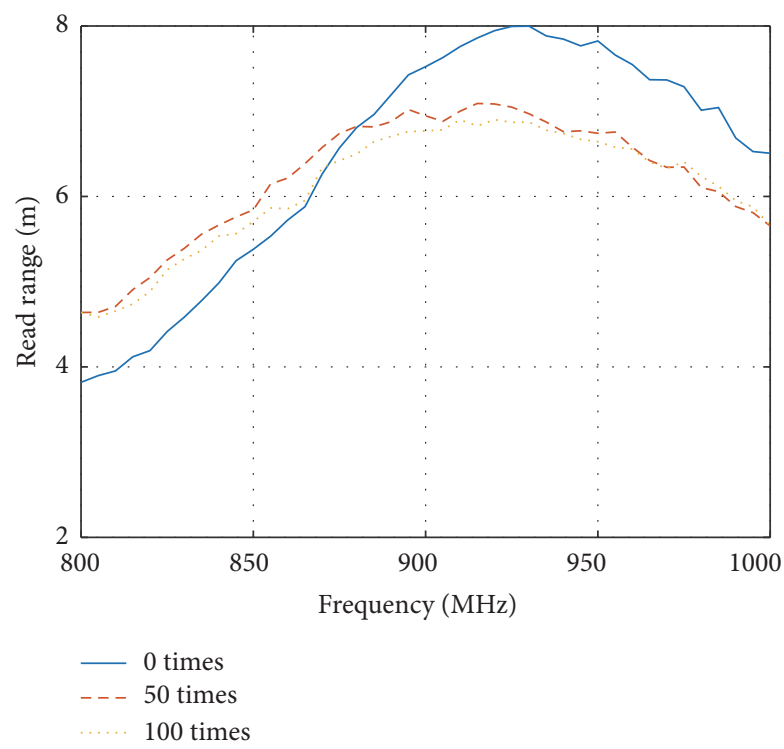

(a)

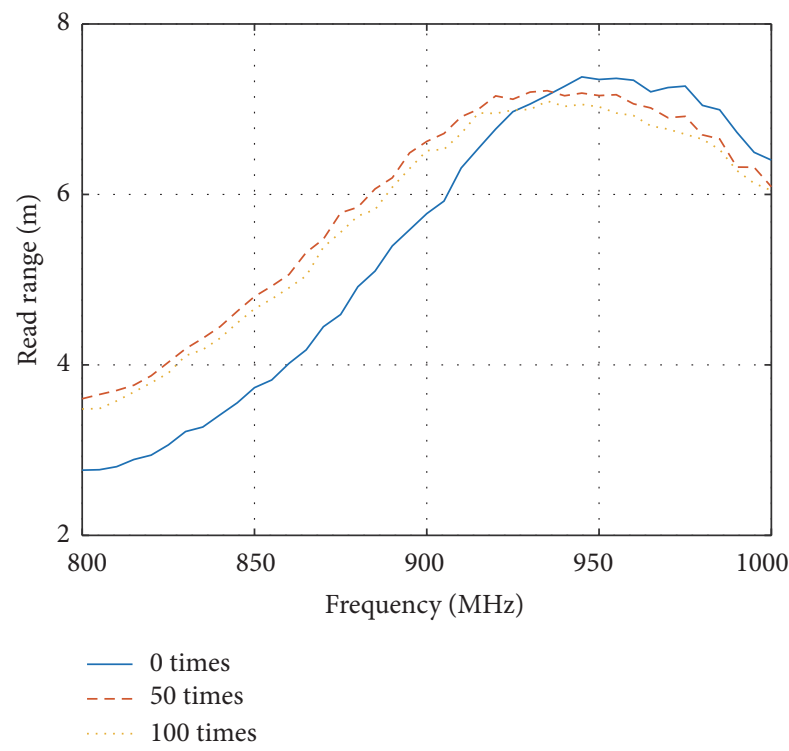

(b)

FIGURE 10: Repeated stretching test of partial vertical pattern with sewed IC (a) and glued IC (b).

TABLE 2: The maximum stretching lengths (\% of the initial length) of tag patters on Fabric 1 and Fabric 2.

\begin{tabular}{lcc}
\hline Tag pattern & \multicolumn{2}{c}{ Maximum length (\%) } \\
\hline N/A & Fabric 1 & Fabric 2 \\
1 & $180 \%$ & $180 \%$ \\
2 & $150 \%$ & $125 \%$ \\
3 & $125 \%$ & $120 \%$ \\
4 & $140 \%$ & $120 \%$ \\
5 & $110 \%$ & $115 \%$ \\
\hline
\end{tabular}

placed at a continually strained location, for example, for the purpose of strain monitoring. In such harsh conditions, one possibility would be to use a suitable coating to protect the antenna-IC interconnection from any mechanical stress, as suggested in a recent washing reliability study of electrotextile RFID tags [18]. Next, we will also study the reliability of these tags in less severe strain conditions.

\section{Conclusions}

We studied the fabrication and impact of strain on the performance of passive UHF RFID textile tags with embroidered antennas on two structurally dissimilar substrates. Two fabrication methods, sewing and gluing, were also tested for the antenna-IC interconnections. According to our results, the characteristics of the fabric substrate have a huge effect on the fabrication of the tags. Our measurement results showed that a simple contour pattern and a partial vertically sewed pattern can be utilized to fabricate stretchable tag antennas on an elastic band-based substrate. However, both the sewed and glued interconnections showed some reliability/reproducibility issues that need to be solved. Also, the degree of stretching on different parts of clothing will be examined and further reliability testing will be done. Future work also includes electromagnetic optimization of the antennas and their measurements near the human body.

\section{Competing Interests}

The authors declare that there is no conflict of interests regarding the publication of this paper.

\section{Acknowledgments}

This research work was supported by the European Commission AdvIOT IRSES project, Academy of Finland, TEKES, and Jane and Aatos Erkko Foundation.

\section{References}

[1] A. Sani, M. Rajab, R. Foster, and Y. Hao, "Antennas and propagation of implanted RFIDs for pervasive healthcare applications," Proceedings of the IEEE, vol. 98, no. 9, pp. 1648-1655, 2010.

[2] A. Yakovlev, S. Kim, and A. Poon, "Implantable biomedical devices: wireless powering and communication," IEEE Communications Magazine, vol. 50, no. 4, pp. 152-159, 2012.

[3] J. Grosinger, "Feasibility of backscatter RFID systems on the human body," EURASIP Journal on Embedded Systems, vol. 2013, article 2, 2013.

[4] E. Moradi, K. Koski, T. Björninen et al., "Miniature implantable and wearable on-body antennas: towards the new era of wireless body-centric systems," IEEE Antennas and Propagation Magazine, vol. 56, no. 1, pp. 271-291, 2014.

[5] S. Merilampi, H. He, L. Sydänheimo, L. Ukkonen, and J. Virkki, "The possibilities of passive UHF RFID textile tags as comfortable wearable sweat rate sensors," in Proceedings of the Progress in Electromagnetics Research Symposium (PIERS '16), Shanghai, China, August 2016. 
[6] P. Salvo, F. Di Francesco, D. Costanzo, C. Ferrari, M. G. Trivella, and D. De Rossi, "A wearable sensor for measuring sweat rate," IEEE Sensors Journal, vol. 10, no. 10, pp. 1557-1558, 2010.

[7] M. Akbari, J. Virkki, L. Sydanheimo, and L. Ukkonen, "Toward graphene-based passive UHF RFID textile tags: A Reliability Study," IEEE Transactions on Device and Materials Reliability, vol. 16, no. 3, pp. 429-431, 2016.

[8] J. Wang, J. Liu, J. Virkki et al., "Brush-painting and photonical sintering of copper and silver inks on cotton fabric to form antennas for wearable ultra-high-frequency radio-frequency identification tags," Textile Research Journal, vol. 86, no. 15, pp. 1616-1624, 2016.

[9] E. Moradi, T. Björninen, L. Ukkonen, and Y. Rahmat-Samii, "Effects of sewing pattern on the performance of embroidered dipole-type RFID tag antennas," IEEE Antennas and Wireless Propagation Letters, vol. 11, pp. 1482-1485, 2012.

[10] M. E. Berglund, J. Duvall, C. Simon, and L. E. Dunne, "Surfacemount component attachment for e-textiles," in Proceedings of the 19th ACM International Symposium on Wearable Computers (ISWC '15), pp. 65-66, ACM, Osaka, Japan, September 2015.

[11] E. R. Post, M. Orth, R. R. Russo, and N. Gershenfeld, "E-broidery: design and fabrication of textile-based computing," IBM Systems Journal, vol. 39, no. 3-4, pp. 840-860, 2000.

[12] T. Linz, C. Kallmayer, R. Aschenbrenner, and H. Reichl, "Embroidering electrical interconnects with conductive yarn for the integration of flexible electronic modules into fabric," in Proceedings of the 9th IEEE International Symposium on Wearable Computers (ISWC '05), pp. 86-89, Osaka, Japan, October 2005.

[13] T. Linz, R. Vieroth, C. Dils et al., "Embroidered interconnections and encapsulation for electronics in textiles for wearable electronics applications," Advances in Science and Technology, vol. 60, pp. 85-94, 2008.

[14] B. Ivsic, D. Bonefacic, and J. Bartolic, "Considerations on embroidered textile antennas for wearable applications," IEEE Antennas and Wireless Propagation Letters, vol. 12, pp. 1708-1711, 2013.

[15] R. Rahimi, W. Yu, T. Parupudi, M. Ochoa, and B. Ziaie, "A lowcost fabrication technique for direct sewing stretchable interconnetions for wearable electronics," in Proceedings of the 18th International Conference on Solid-State Sensors, Actuators and Microsystems (TRANSDUCERS '15), pp. 1350-1353, Anchorage, Alaska, USA, June 2015.

[16] B. Huyghe, H. Rogier, J. Vanfleteren, and F. Axisa, "Design and manufacturing of stretchable high-frequency interconnects," IEEE Transactions on Advanced Packaging, vol. 31, no. 4, pp. 802-808, 2008.

[17] J. Virkki, T. Björninen, S. Merilampi, L. Sydänheimo, and L. Ukkonen, "The effects of recurrent stretching on the performance of electro-textile and screen-printed ultra-high-frequency radio-frequency identification tags," Textile Research Journal, vol. 85, no. 3, pp. 294-301, 2015.

[18] S. Wang, N. L. Chong, J. Virkki, T. Björninen, L. Sydänheimo, and L. Ukkonen, "Towards washable electrotextile UHF RFID tags: reliability study of epoxy-coated copper fabric antennas," International Journal of Antennas and Propagation, vol. 2015, Article ID 424150, 8 pages, 2015. 


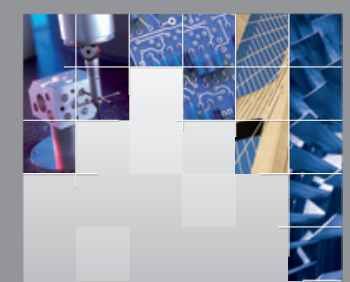

\section{Enfincering}
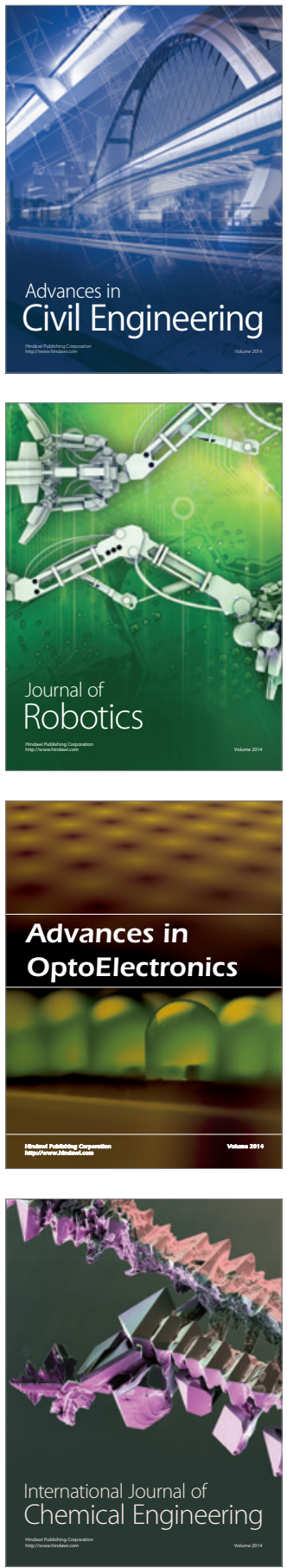

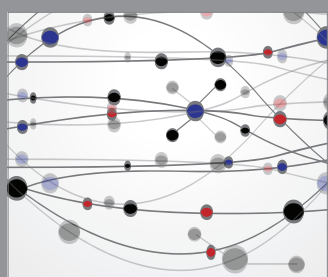

The Scientific World Journal

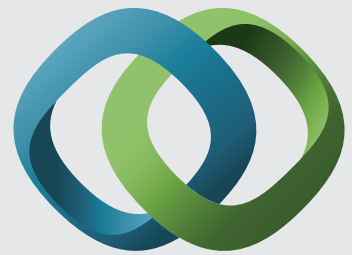

\section{Hindawi}

Submit your manuscripts at

https://www.hindawi.com
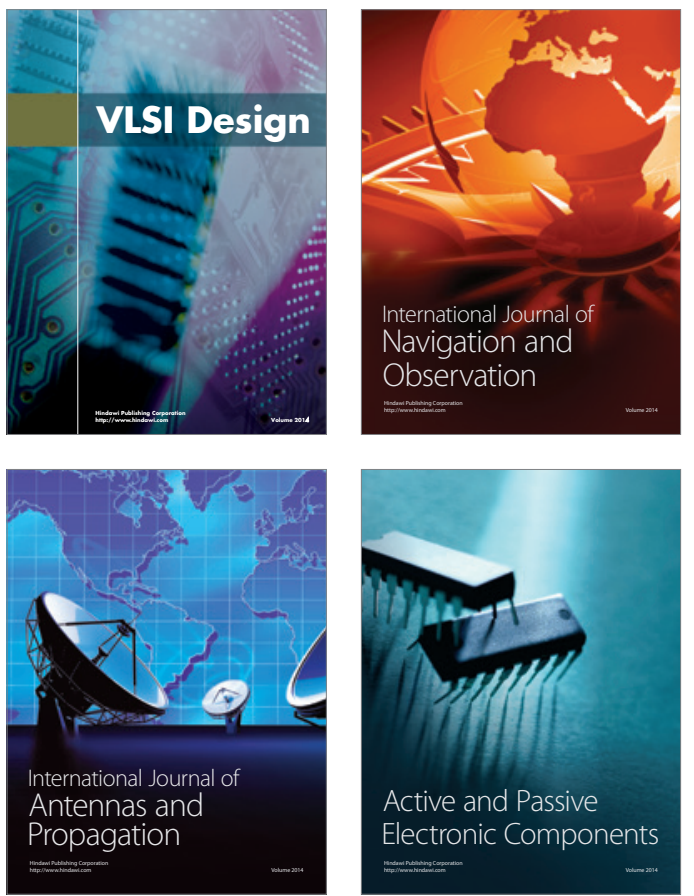
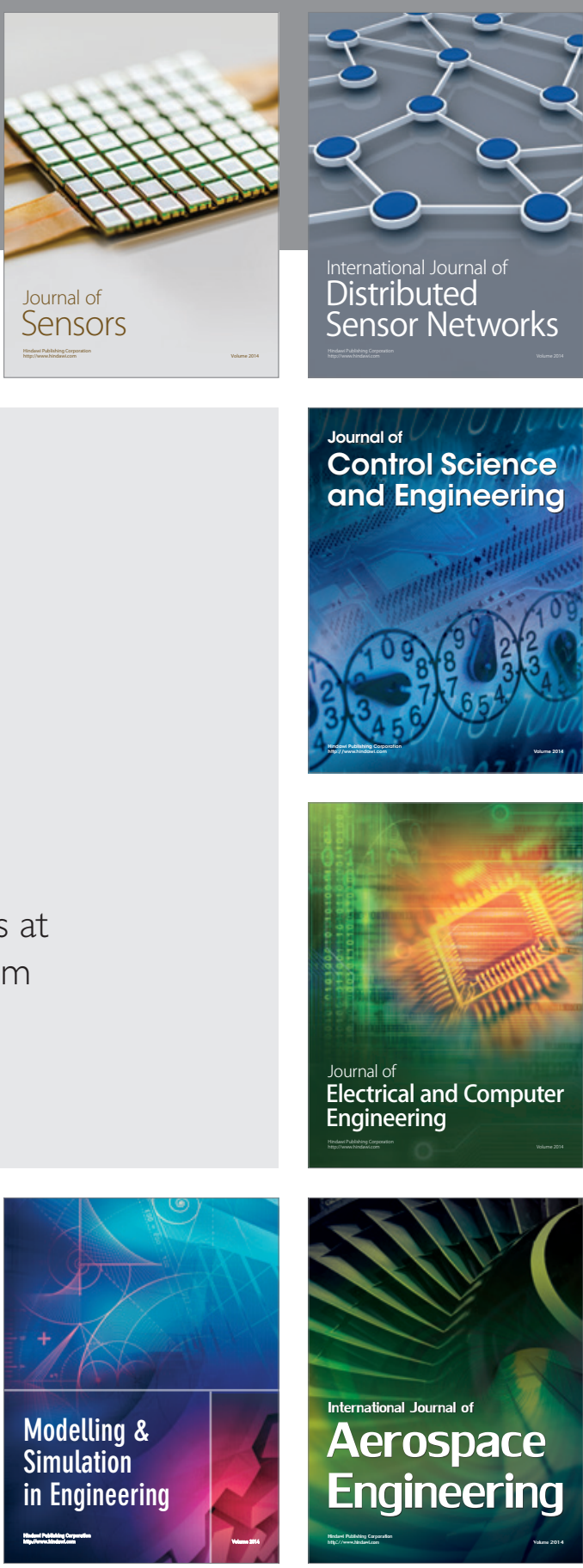

International Journal of

Distributed

Sensor Networks

$-$

Joumal of

Control Science

and Engineering
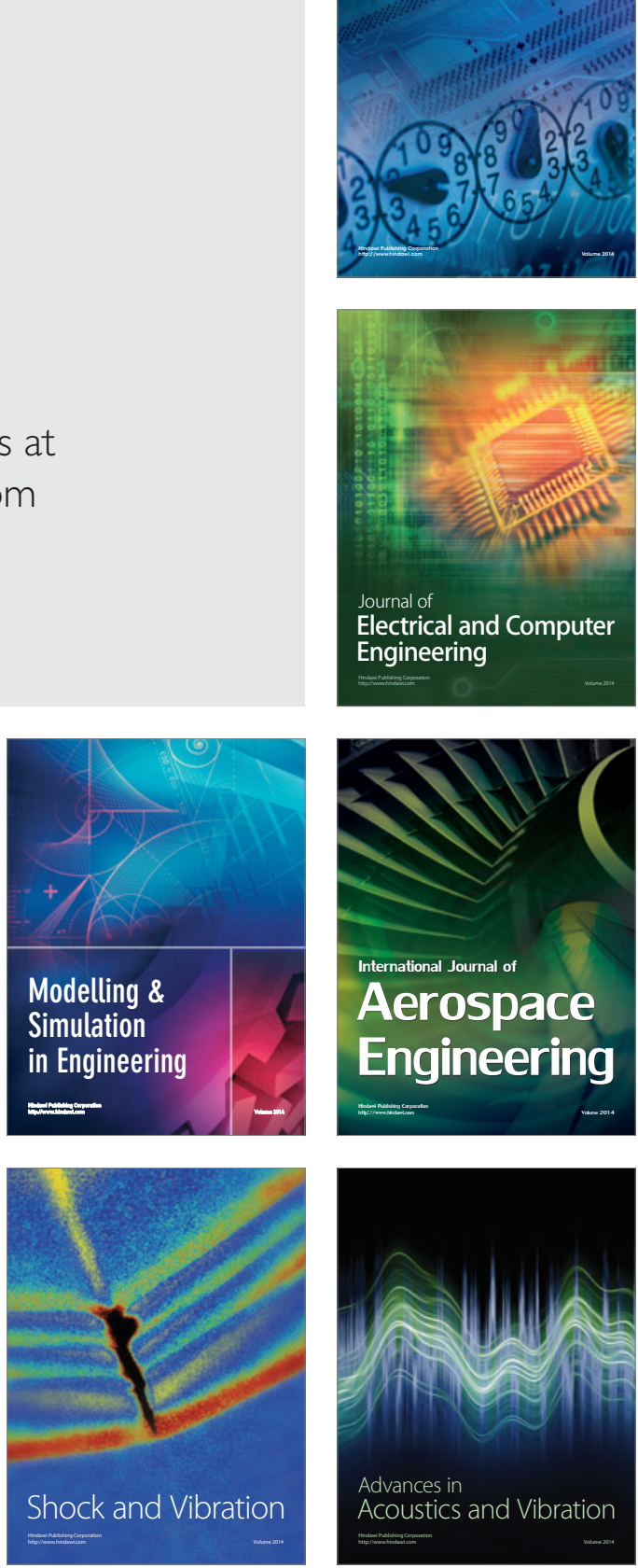